\title{
AMPLIANDO O CAMPO DE INTERVENÇÃO DA EDUCAÇÃO FÍSICA ESCOLARA PARTIR DAANÁLISE DA ESCADA DA APTIDÃO PARA TODA A VIDA ${ }^{1}$
}

\author{
FABIANo Pries Devide ${ }^{2}$ \\ Gabriela Aragão Souza de Oliveira ${ }^{3}$ \\ Marcos SANTOS Ferreira ${ }^{4}$
}

\section{RESUMO}

Este artigo objetiva analisar o modelo da Escada da Aptidão para Toda a Vida (EATV) à luz do ideário da Promoção da Saúde (PS) e da Cultura Corporal do Movimento (CCM), no sentido de ampliar a proposta de Educação Física Escolar (EFE). Primeiramente, constatamos que a EATV enfatiza a aquisição de saúde via aptidão física; ignora aspectos sócio-políticos e econômicos da saúde; não supera a relação causal entre exercício e saúde; e fragmenta os seus conteúdos. Num segundo momento, sugerimos um redirecionamento da EATV através da exposição de uma Proposta Temática para a EFE, que pressupõe a transmissão de outros conteúdos, visando à formação de um aluno crítico no que concerne ao consumo da CCM.

PALAVRAS-CHAVE: educação física escolar - promoção da saúde - cultura corporal do movimento.

1 Trabalho desenvolvido no extinto Grupo de Estudos em Educação Física e Promoção da Saúde da UFRRJ.

2 Doutor em Educação Física pela Universidade Gama Filho/RJ, professor adjunto da Universidade Salgado de Oliveira/RJ e do Centro Universitário Augusto Motta/RJ.

3 Mestra em Educação Física pela Universidade Gama Filho/RJ e professora da graduação em Educação Física da Universidade Gama Filho.

4 Mestre em Educação Física pela Universidade Federal do Rio de Janeiro e professor da graduação em Educação Física da Universidade do Estado do Rio de Janeiro. 


\section{INTRODUÇÃO}

Tossa interação com alunos do ensino fundamental e médio nos faz 1 inferir que as pessoas crescem acreditando em certos mitos referentes ao exercício, entre eles o da crença na relação causal entre a prática do exercício e a saúde, por não possuírem os conhecimentos necessários para analisá-los criticamente. Esta situação nos faz pressupor que a Educação Física Escolar não tem cumprido sua função. Consideramos que os professores de Educação Física têm responsabilidade na modificação deste cenário, o que pode ser concretizado através da socialização de conhecimentos acerca do exercício físico, do desenvolvimento da consciência crítica e do desvelamento dos condicionantes sociais do status de saúde.

A EF pode redirecionar sua prática na escola, contribuindo para a criação de estilos de vida ativos para toda a vida (ANDREWS, 1990), mediada pelas idéias da Promoção da Saúde (FARIA JÚNIOR, 1991) e da Cultura Corporal do Movimento (COLETIVO DE AUTORES, 1992). Em busca de uma EF que se legitime no espaço escolar, o presente estudo tem como objetivo realizar uma análise da proposta da Escada da Aptidão para Toda a Vida (EATV) idealizada por Charles Corbin (1981), com vistas a ampliar a intervenção da EFE.

Em decorrência da relação histórica da EF com a saúde (GHIRALDELLI JÚNIOR, 1992; SOARES, 1994; CARVALHO, 1995), a relevância deste estudo repousa no fato de contribuir para a reflexão sobre uma EFE compromissada com essa questão, buscando superar o caráter biologicista que vem assolando a transmissão de seus conteúdos, particularmente na escola. Assim, na primeira parte do texto apresentamos a EATV e os princípios da PS; passamos à sua análise, e com o objetivo de ampliar a proposta da EATV, apresentamos um elenco de propostas temáticas e conteúdos a serem trabalhados na EF escolar.

\section{AMPLIANDO A DISCUSSÃO}

A EATV, idealizada por Charles Corbin, citado por Nahas e Corbin (1992), propõe que a função da EFE é fazer com que, ao final dos anos escolares, os alunos tenham "autonomia" programas de exercícios físicos. Antes de apresentarmos os resultados da 
análise da EATV, entendemos que se faz necessária uma revisão dos aspectos referentes a sua proposta, assim como de alguns pontos do referencial teórico da Promoção da Saúde, referenciais ainda pouco difundidos na EF.

\section{Escada da aptidão para toda a vida}

A EATV é desenvolvida em diversas fases, simbolizadas por degraus que devem ser transpostos no decorrer dos anos escolares, de acordo com a figura a seguir:

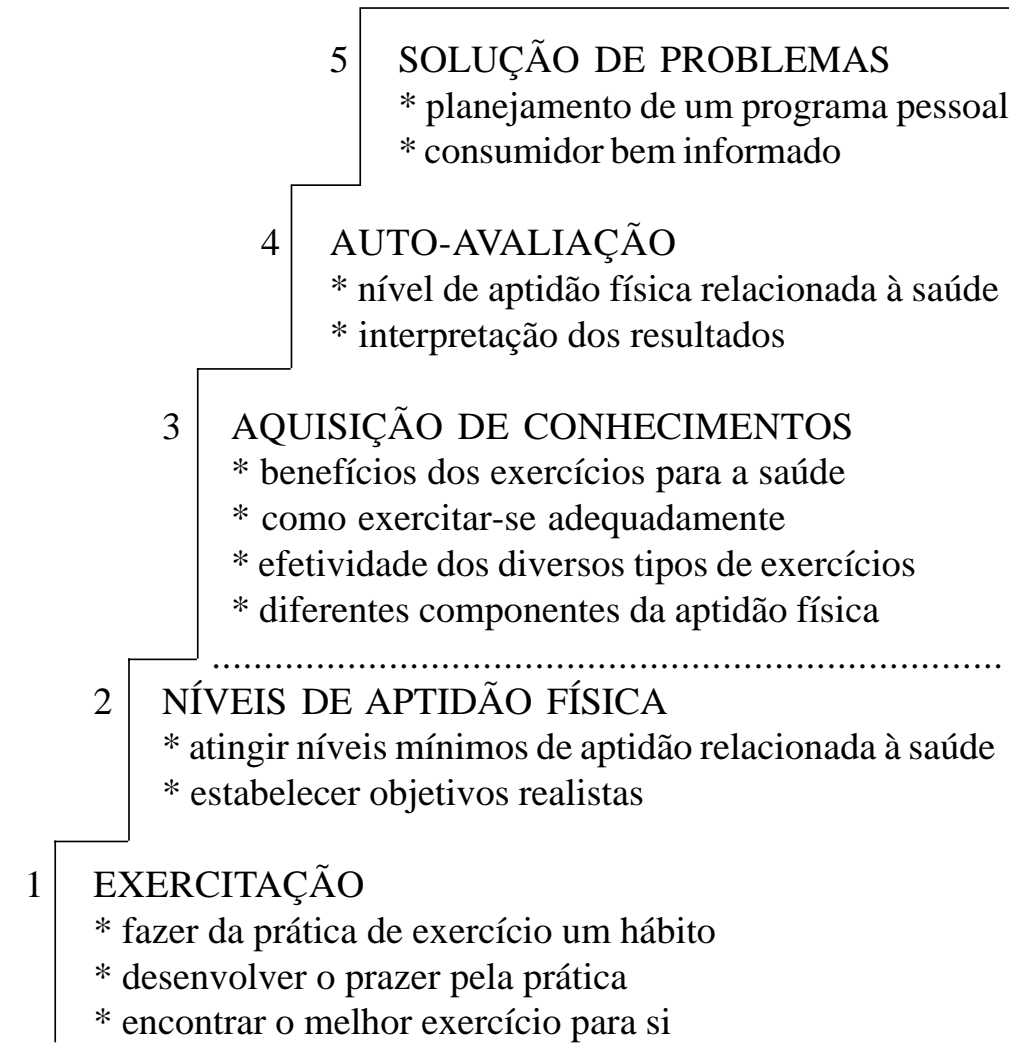

Figura 1 - Escada da Aptidão para Toda a Vida (Fonte: adaptada de Corbin, Fox e Whitehead, 1987) 
O primeiro degrau é representado pelos exercícios. O principal objetivo é fazer com que os alunos sejam ativos desde os seus primeiros anos escolares. As atividades devem ser adequadas aos alunos para que sintam prazer em realizá-las: "crianças que se envolvem em atividades físicas porque sentem prazer tendem a se tornar adultos mais ativos fisicamente" (NAHAS; CORBIN, 1992, p.53).

$\mathrm{O}$ segundo degrau diz respeito à aquisição de aptidão física. Nesse estágio, o autor afirma que só será desenvolvida a aptidão se o aluno for fisicamente ativo (primeiro degrau). Para o desenvolvimento do ensino da aptidão física para toda a vida, poder-se-ia somente desenvolver os cinco componentes da aptidão relacionada com a saúde: resistência muscular, força, flexibilidade, composição corporal e resistência cardio-respiratória (FARIA JÚNIOR, 1991). ${ }^{6}$

Contudo, do segundo degrau para o terceiro é demarcada uma linha pontilhada, significando a atitude que muitos professores adotam quando seus alunos atingem níveis de aptidão satisfatórios. O ponto crucial é se os alunos, apesar de aptos fisicamente, adotarão um estilo de vida ativo, uma vez que não conhecem os benefícios do exercício, e como planejar e avaliar programas. ${ }^{7}$

O terceiro degrau diz respeito aos conhecimentos referentes $\grave{a}$ aptidão física e ao exercício. Neste ponto, o aluno toma conhecimento dos benefícios do exercício para o seu status de saúde, da maneira correta de exercitar-se, da efetividade dos diversos tipos de exercícios e dos diferentes componentes da aptidão física (NAHAS, CORBIN, 1992). Assim, pressupõe-se que o aluno começa a desenvolver os seus próprios esquemas de exercícios, tomando decisões e selecionando aqueles de acordo com os seus interesses, conquistando certa autonomia em relação ao professor.

$\mathrm{O}$ professor de EF tem, entre outras funções, a de informar os alunos sobre os diversos fatores interventores na sua saúde, o que tende a levá-los a adotar atitudes mais positivas em relação à atividade física relacionada à saúde (FRANCALACCI; NAHAS, 1995). Nesse sentido, a EATV propõe que se os professores desejam desenvolver estilos de vida ativos em seus alunos, não devem simplesmente avaliá-los, mas sim ensiná-los a se auto-avaliar, pois não poderão acompanhá-los após sua saída da escola.

Assim, o quarto degrau refere-se à auto-avaliação da aptidão física. Nesse estágio, os alunos são sujeitos a testes, nos quais devem 
estabelecer objetivos individuais, para mais tarde serem capazes de avaliar os componentes da aptidão relacionada à saúde, interpretando os resultados para utilizá-los no planejamento de seu programa individual de exercícios.

No quinto degrau, o aluno é preparado para solucionar problemas e tomar decisões a respeito de sua prática de exercícios. Pode escolher, dentre as atividades que experimentou, as que mais aprecia para incorporá-las em seu programa de exercícios. O aluno tem conhecimento suficiente para tornar-se um consumidor bem informado, não sendo influenciado por informações equivocadas sobre os exercícios.

Neste ponto da EATV, o mais importante é a autonomia criada pelo aluno, no que diz respeito ao planejamento de seus próprios programas pessoais, independentemente da presença do professor (CORBIN; FOX, 1986). Além disso, ele exercita-se ciente do valor e dos benefícios da prática regular de exercícios para o seu bem-estar e sua saúde. Portanto, de acordo com a EATV, não basta desenvolver a aptidão física relacionada à saúde. É necessário abordar os aspectos cognitivos referentes à aptidão física e aos exercícios, para que os alunos tomem atitudes a respeito da criação de estilos de vida ativos para toda a vida.

Contudo, a nosso ver, na escola, mais do que corpos aptos fisicamente e conhecimentos sobre a aptidão física relacionada à saúde, é necessário desenvolvermos a consciência para a tomada de decisões e atitudes referentes ao consumo da cultura corporal de movimento, além do conhecimento da aptidão física relacionada à saúde e à prática regular de exercícios físicos, o que pressupõe a discussão de outros temas e conteúdos nas aulas de EF.

\section{Promoção da Saúde}

A discussão sobre a PS feita por Faria Júnior (1991) se deu a partir de um documento produzido pela Organização Mundial da Saúde, intitulado Health promotion: a discussion document of the concept and principles (WHO, 1984).

Os princípios básicos da PS são o reconhecimento da natureza multifatorial e coletiva da saúde, a proposta de sua desmedicalização e a educação para a saúde. De acordo com a WHO (1984), os cinco objetivos que orientam o ideário da PS são: (a) focalizar a população como um 
todo e não apenas os grupos de risco; (b) ser voltada para muitos fatores que influenciam a saúde; (c) requerer a participação de toda a comunidade, alguma coisa que envolva a aquisição - individual e coletiva - de estilos de vida; (d) envolver uma ampla variedade de estratégias e agências - comunicação, educação, legislação, medidas fiscais, mudanças organizacionais, desenvolvimento comunitário e atividades espontâneas locais, contra os azares da saúde; (e) envolver profissionais de saúde que viabilizem a PS em suas práticas.

Faria Júnior (1991) aborda os princípios da PS com foco direcionado para a EF, uma vez que, estando relacionada historicamente com a saúde, havia necessidade de uma discussão ampliada e uma reflexão sobre este aspecto, o que o autor procurou fazer sob a luz deste conjunto de idéias, que consiste em um posicionamento crítico sobre a questão da saúde, servindo de rico suporte para discussão do binômio exercício-saúde na área da EF e, portanto, para a análise da proposta da EATV.

Diante deste quadro, Faria Júnior (1991) enunciou as relações de compromisso da EF com a PS, ressaltando o seu papel no apoio às pessoas e comunidades a adotarem e a manterem práticas saudáveis, a usarem os serviços de saúde disponíveis, a desenvolverem a consciência crítica, a atingirem autocapacitação para a tomada de decisões (individual e/ou coletivamente), aprimorando o seu status de saúde. Desta forma, dentre os quatro pontos básicos - natureza multifatorial e coletiva da saúde, desmedicalização e educação para a saúde - o autor focaliza mais explicitamente o último. Entretanto, sua discussão a respeito da educação para a saúde não desconsidera os outros três aspectos que coexistem durante o seu texto.

A PS enfatiza a importância do envolvimento comunitário nas questões da saúde individual e coletiva. A transmissão de conhecimentos à população contribui para que a comunidade tenha responsabilidade sobre sua saúde, explicitando seus problemas, reivindicando e sugerindo soluções.

A desmedicalização admite que a saúde não é só uma questão da medicina, uma vez que envolve diversos campos de conhecimento, reunindo o esforço de outros profissionais: enfermeiros, assistentes sociais, professores, sociólogos, psicólogos, nutricionistas etc. No entanto, não tem havido cooperação efetiva entre eles, uma vez que a palavra final tende a ser do médico, às vezes, mesmo quando se refere à prática de exercícios. 
O trabalho conjunto destes profissionais deve ter como objetivo educar as pessoas a adotarem práticas que otimizem a sua saúde e a de sua comunidade, o que constitui a educação para a saúde. Seja na escola ou na comunidade, a educação para a saúde tem por objetivo fazer as pessoas assumirem atitudes que as conduzam a uma melhor qualidade de vida. Tones (1986) encara a educação para a saúde sob três modelos: Preventivo, Político Radical e de Autocapacitação. ${ }^{8}$

Neste contexto, a EF deve justificar seus conteúdos ${ }^{9}$ voltando-os para a PS, através da aquisição de estilos de vida ativos e hábitos saudáveis por parte da comunidade e não apenas de algumas pessoas. Esse estilo de vida é mais do que a adesão à prática de exercícios físicos, mas a aquisição de hábitos que otimizem o seu status de saúde e de sua comunidade: "a participação da comunidade amplia a concepção de estilos de vida do nível individual para o coletivo e exige da educação física novas responsabilidades, papel e ações interativas" (FARIA JÚNIOR, 1991, p. 26).

Desta forma, a EF compromissada com a PS deve levar os alunos à exercitação, a desenvolverem conhecimentos sobre a prática física, e principalmente, a se conscientizarem acerca de sua importância e benefícios para a vida, possibilitando a identificação dos fatores que os impedem, por vezes, de praticar exercícios regularmente. Neste sentido, Farinatti (1994, p. 47) afirma que:

O planejamento e execução de programas visando ao engajamento em atividades corporais (na escola ou fora dela) é, assim, uma questão não só de saúde pública - como encarada por alguns - mas de cidadania. Só assim poderemos construir com o educando a noção de que a oportunização à prática de atividades físicas constitui-se um direito tão fundamental quanto o acesso à educação, saneamento básico ou transporte público - pelo qual, portanto, vale a pena lutar.

\section{RESULTADOS DA ANÁLISE E DISCUSSÃO}

Após a discussão da EATV e da PS, apresentaremos as categorias criadas por nós a partir da análise sistemática dos textos selecionados sobre a EATV, seguidas de sugestões de temáticas que permeiam a apresentação de conteúdos que consideramos relevantes para a construção e consolidação de uma proposta crítica para a EFE, com base em nossa 
atuação enquanto professores da rede estadual de educação do Rio de Janeiro. ${ }^{10}$

\section{Biologização da saúde}

Após a análise da proposta da EATV, nota-se que os níveis de aptidão relacionados à saúde e à prática regular de exercícios - importantes para a criação de estilos de vida ativos - são apresentados como fatores suficientes para a aquisição de saúde e bem-estar. Assumindo o aspecto multifatorial da saúde, observa-se, na proposta da EATV, um reducionismo da saúde ao seu aspecto físico, ignorando seus determinantes sócio-políticos, econômicos e culturais, adotando-se, pois, um caráter biologicista.

Esta inferência pode ser constatada no discurso de Nahas e Corbin (1992, p. 54) quando afirmam que

níveis razoáveis de aptidão física são importantes para a boa saúde e o bem-estar, e é pela prática regular de atividades que estes níveis serão atingidos (limitados, de certa forma, pelas características hereditárias individuais).

Corbin e Fox (1988, p. 74) também retratam a condição biologicista da saúde quando a relacionam unicamente com a aptidão física:

O maior objetivo dos programas de educação física deve ser o de equiparar todos os alunos com habilidades de solução de problemas de aptidão assim como as atitudes positivas para o envolvimento na atividade física. Em longo prazo, este objetivo promoverá as chances de nossos alunos obterem aptidão e saúde para toda a vida.

\section{Culpabilização da vítima}

Observamos o aspecto da culpabilização da vítima quando a saúde é encarada apenas como o resultado de estilos de vida ativos. Ou seja, não se reconhecem os condicionantes sócio-políticos e econômicos, assim como o caráter coletivo da saúde, que impedem, por vezes, que as pessoas adotem um estilo de vida ativo.

Constatamos tal culpabilização quando Nahas e Corbin (1992) se referem ao terceiro degrau da EATV, no qual o aluno deve tomar conhe- 
cimento dos benefícios do exercício para o seu status de saúde, a maneira correta de exercitar-se e a efetividade dos diversos tipos de exercícios e dos diferentes componentes da aptidão física. Neste contexto, toda a responsabilidade em ser saudável recai, portanto, sobre o aluno, pormenorizando e individualizando a questão do ser saudável.

\section{Causalidade exercício-saúde}

Durante todas as etapas da EATV, reforça-se o fato de o aluno, durante os anos escolares, adquirir os conhecimentos necessários para poder programar e avaliar os seus esquemas de exercícios, adquirindo autonomia frente ao professor, mantendo bons níveis de aptidão física para toda a vida.

Contudo, esse conhecimento não será de fato útil, se o aluno não reconhecer o aspecto multifatorial da saúde. Isso acarretará a formação de um aluno que, ao egressar da escola, tenderá a perpetuar a relação causal entre o exercício e a saúde. Além disso, com uma visão singular da saúde, não terá condições de identificar, reivindicar e propor soluções para os diversos problemas que atuam na sua saúde e na de sua comunidade, que se torna incapaz de organizar-se para ações que busquem melhor qualidade de vida.

\section{Etapismo}

O autor divide a EATV em degraus que simbolizam etapas pelas quais o aluno deve transpor no decorrer dos anos escolares, estipulando um grau de dependência entre um degrau e outro. Isso é observado quando Nahas e Corbin (1992, p. 53) afirmam: "O desenvolvimento da aptidão física ocorrerá se as crianças e jovens forem fisicamente ativos" (degrau 1).

Ainda confirmando essa dependência, Corbin e Fox (1986, p. 207) dizem que

as pessoas que aprenderam a selecionar as atividades que satisfazem as suas próprias necessidades e interesses (degrau 4) e que conhecem como avaliar os seus próprios níveis de aptidão (degrau 5) são capazes de subir o sexto e último degrau da escada da aptidão; podem agora saber como resolver os seus próprios problemas de aptidão. 
Confrontamos essa posição com o princípio curricular da simultaneidade dos conteúdos abordado pelo Coletivo de Autores (1992), que preconiza a apresentação dos conteúdos de forma simultânea, evitando o etapismo e os pré-requisitos para o conhecimento, que dificultam a visão de totalidade do aluno, que assimila os conteúdos de forma isolada e sem relação com os outros. A diferença constatada ao se adotar o princípio da simultaneidade é a maneira como são apresentados os conteúdos de um nível de aprendizagem para o outro. Dessa forma, os conhecimentos a respeito da aptidão física relacionada à saúde, a importância de estilos de vida ativos para toda a vida, e o elenco de conteúdos e propostas temáticas por nós reunidos na segunda parte deste texto, podem ser ensinados de diferentes maneiras no ensino fundamental, ou seja, na posição de professores, podemos ensinar o que é a frequiência cardíaca do $3^{\circ}$ e $4^{\circ}$ ciclos do ensino fundamental até o ensino médio, abordando este conteúdo com um grau de complexidade progressivo.

\section{AMPLIANDO O CAMPO DE INTERVENÇÃO DA EFE A PARTIR DA ANÁLISE DA EATV}

Ao adotar a proposta da EATV, consideramos que a EFE esbarra em limitações para a reflexão acerca dos problemas sociais referentes à prática e ao consumo da cultura corporal do movimento e da sua relação com a saúde. Desta maneira, a EATV foi um avanço para a EFE, ainda preocupada com o modelo hegemônico do esporte, através do ensino de regras, táticas e técnicas desportivas (BRACHT, 1997; CAPARROZ, 1997).

Da perspectiva da EATV, a EF pode desenvolver a aptidão física e os conhecimentos sobre a exercitação, a programação e a avaliação de esquemas de exercícios, o que possibilita o início da construção de uma identidade procurada através de sua história. ${ }^{11}$ Contudo, nossa proposta é ampliar a EATV da ótica do ideário da PS e da cultura corporal, visando a propiciar ao aluno, além de saber exercitar-se corretamente e com autonomia na busca de estilos de vida ativos para toda vida, reconhecer, apontar, reivindicar e propor soluções para os diversos fatores que influenciam na sua saúde e da comunidade em que vive, politizando-se frente à questão da saúde e de seus determinantes, que vão além da prática de exercícios físicos; tornando-se um consumidor crítico do movimento. 
Assim, no intuito de enriquecer a proposta da EATV, sugerimos alguns temas já trabalhados por nós nas escolas, que pensamos, devem perpassar os conteúdos da EFE, para que possam viabilizar ações transformadoras na sociedade.

\section{PROPOSTA TEMÁTICA PARA A EFE NA EDUCAÇÃO FUNDAMENTAL}

Corroboramos aqui, com a proposta de conteúdos do Coletivo de Autores (1992), quais sejam: os jogos, as brincadeiras, a dança, os esportes, as ginásticas e as lutas, que constituem a cultura corporal do movimento. Articulando-se com esses conteúdos, apresentaremos alguns temas possíveis para o estudo e a discussão que têm estado articulados nos projetos político-pedagógicos de nossas práticas em escolas da rede estadual do Rio de Janeiro, ${ }^{12}$ com turmas do ensino fundamental e médio (SOUZA DE OLIVEIRA; DEVIDE, 2001).

O primeiro tema que propomos é a Promoção da Saúde. Temos trabalhado a PS com os alunos enquanto conjunto de idéias capaz de ampliar a discussão do binômio exercício-saúde e conscientizá-los sobre o seu conceito multifatorial e a sua relação com a prática regular de atividade física; além de possibilitar à EF desempenhar um papel na educação para a saúde dos alunos, um dos aspectos principais a ser tratado na EFE.

A história é um dos aspectos relevantes no trato de qualquer conteúdo da EFE. Por possibilitar a apresentação dos antecedentes que deram origem às atuais formas que constituem a cultura corporal, esclarecer os significados que estas formas tiveram ao longo do tempo, discutir quais os papéis da atividade física nas sociedades humanas, atribuindo-lhes a noção de historicidade, a história pode resgatar o valor de atividades já esquecidas ou desvalorizadas pelas sociedades contemporâneas.

Os aspectos técnicos referem-se a como fazer a atividade, entendendo-a como produto sempre inacabado, passível de (re)construção a cada nova experiência da aula. Assim, a partir da técnica oficial do desporto, por exemplo, os professores podem problematizar com os alunos as técnicas oficiais de execução de habilidades, recriando novas formas de saltar, correr, lançar, arremessar e outras.

A competição é um tema relevante a ser abordado na EFE. Muitas vezes, a ênfase exclusiva do rendimento traz a conseqüente perda do caráter 
prazeroso das atividades, contribuindo para a criação do exército de alunos que desprezam a EF na escola. A participação, em detrimento da exclusão causada pela competição exacerbada, deve ser estimulada para que os alunos desenvolvam o senso de curiosidade, da busca do novo, do envolvimento e do prazer em vivenciar, aprender e ensinar, do banimento da mera repetição mecânica, de práticas vazias de significado, da prática pela prática.

A discussão sobre o lazer e tempo livre também tem sido feita em nossas aulas de EF na escola. A partir da realidade vivida dos alunos, podemos problematizar as mudanças nos modos de produção do quotidiano, enfatizando o aumento do tempo livre e a possibilidade de sua utilização para o desenvolvimento da criatividade humana através da cultura corporal, além das questões sociais acerca do lazer e suas barreiras em função das diferenças sociais.

A influência da mídia na consolidação de representações sociais, mitos e crenças associadas à prática de atividade física, como o uso do esporte e da atividade física para interesses capitais de ascensão social, determinados esportes contribuírem para a violência, entre outros aspectos, é tema que pode ser apresentado aos alunos na EFE e que desencadeia discussões frutíferas.

Os conhecimentos sobre o corpo, como a fisiologia do exercício e as modificações no funcionamento do corpo durante a atividade física; a freqüência cardíaca (classificação, locais de medição, importância, maneiras de calcular); os mitos relacionados aos exercícios veiculados no quotidiano; as dicas para a prática correta de exercícios; e as qualidades físicas e sua importância no quotidiano, são temas que podem permear a prática de diferentes elementos da cultura corporal e já trabalhados por nós com sucesso na escola (DEVIDE; RIZZUTI, 1999).

Por fim, o tema da co-educação pode ser trabalhado na EFE com vistas a uma reflexão crítica acerca do sexismo nas práticas corporais, tais como os rótulos atribuídos a determinadas atividades como sendo masculinas ou femininas. O desenvolvimento de aulas mistas em que surjam situações-problema para a discussão das diferenças de cunho sócio-cultural e biológico entre meninos e meninas na prática de atividades físicas é uma rica possibilidade para se trabalhar com esta temática (SARAIVA, 1999). ${ }^{13}$

Neste contexto, consideramos necessário que os conhecimentos abordados nas aulas de EF extrapolem os conteúdos acerca da aptidão física 
relacionada à saúde, proposta pela EATV, ou as idéias da PS. É preciso travar um diálogo entre estas propostas e aquela referente à Cultura Corporal do Movimento, com vistas a alcançar a legitimidade da EF na escola.

Entendemos que a consolidação da EF enquanto disciplina escolar perpassa pela viabilidade dos conteúdos da cultura corporal atravessados por temas de estudo (como os apresentados anteriormente) desenvolvidos com os alunos nos diferentes ciclos da educação básica, através de uma abordagem simultânea e de uma sequiência que possibilite a vivência de todos estes temas em cada um dos ciclos de ensino, num grau de complexidade e aprofundamento cada vez maiores, à medida que vão sendo debatidos e ampliados ao longo dos anos escolares.

Sendo assim, consideramos que a EF pode e deve proporcionar a vivência e a discussão sobre o movimentar-se, a partir dos conteúdos da cultura corporal de movimento (esportes, danças, lutas, jogos, ginástica), nos diferentes momentos e situações-problema das aulas. Debatendo sobre os aspectos históricos, fisiológicos, estéticos, éticos, culturais, sociais e políticos que constituem os temas acima, a EFE poderá criar condições efetivas de formar um aluno crítico, capaz de buscar a transformação da realidade ao seu redor.

\section{CONSIDERAÇÕES FINAIS}

Tais temáticas têm perpassado as discussões ocorridas por ocasião das aulas de EF ministradas por nós em escolas da rede estadual do Rio de Janeiro, enriquecendo a apresentação e o ensino dos conteúdos da disciplina, tornando-os mais próximos da realidade dos alunos, e por isso, despertando o prazer pela prática física, a facilitação de sua aprendizagem e adoção no estilo de vida dos alunos, além de transformar as representações sociais dos alunos acerca da EF enquanto disciplina curricular, em direção à sua crescente valorização.

Broadening the scope for intervention of school physical education from the analysis of the ladder of physical aptitude for life

\section{ABSTRACT}

This article aims at analyzing the model for the Ladder of Physical Aptitude for Life (EATV) in the light of the ideals of Health Promotion (PS) and the Body Culture of 
Movement (CCM), in the sense of broadening the scope for School Physical Education (EFE). Firstly we verified that EATV emphasizes the acquisition of health via physical aptitude: it ignores the social-political and economic aspects of health; it does not surpass the causal relation between exercise and health; and it fragments its contents. Secondly, we suggest a redirecting of EATV through the presentation of a theme proposal for the EFE which implies the transmission of other contents, aiming at creating critical thinking students on the issue of CCM consumption.

KEY WORDS: school physical education - health promotion - body culture of movement.

\section{Ampliando el campo de intervención de la educación física escolar a partir del análisis de la escala de la aptitud para toda la vida}

\section{RESUMEN}

Este artículo objetiva analizar el modelo de la Escala de la Aptitud para Toda la Vida (EATV) a la luz del ideal de la Promoción de la Salud (PS) y de la Cultura Corporal del Movimiento (CCM), en el sentido de ampliar la propuesta de Educación Física Escolar (EFE). Primero, constatamos que la EATV enfatiza la adquisición de salud vía aptitud física; ignora aspectos socio-políticos y económicos de la salud; no supera la relación causal entre ejercicio y salud; y fragmenta sus contenidos. En un segundo momento, sugerimos un redireccionamiento de la EATV a través de la exposición de una Propuesta Temática para la EFE, que presupone la transmisión de otros contenidos, visando la formación de un alumno crítico en lo que se refiere al consumo de la CCM.

PALABRAS-CLAVE: educación física escolar - promoción de la salud - cultura corporal del movimiento.

\section{NOTAS}

5 A palavra "autonomia" está aspeada em função de o aluno, ao fim dos anos escolares, não deter o conhecimento de um professor de educação física, apesar de possuir informações básicas sobre a elaboração e avaliação de um programa de exercícios para si próprio.

6 Porém, se o objetivo principal da EFE é a criação de estilos de vida ativos por toda a vida, outros conteúdos devem ser incluídos nesta escada, os quais abordaremos ainda neste ensaio.

7 Além disso, o professor, muitas vezes, justifica os baixos índices nos testes de aptidão ao comportamento inativo dos alunos, que podem se sentir desencorajados para adotar um estilo de vida ativo, quando muitas vezes este não é o fator determinante dos resultados nesta idade. Na fase pré-pubertária, a exercitação torna-se secundária no 
resultado dos testes de aptidão física relacionada à saúde, uma vez que fatores mais fortes como a hereditariedade e a maturação, que variam de aluno para aluno, têm influência maior no resultado dos testes, tornando-se falho, portanto, usar os seus resultados para inferir-se sobre o estado de saúde física do aluno, assim como interpretar os baixos ou altos scores decorrentes da exercitação ou nãoexercitação (PANGRAZI; CORBIN, 1993).

8 O Modelo Preventivo busca a redução da mortalidade e morbidade da população, coagindo o indivíduo a adotar estilos de vida que previnam a doença, além da utilização correta dos serviços de saúde. É criticado por ignorar as raízes sócio-políticas da saúde, contribuindo para a culpabilização da vítima, por essa não adotar um estilo de vida saudável, além de reforçar a medicalização. O Modelo Político Radical procura descobrir as causas dos problemas da saúde, fazendo com que as pessoas desenvolvam consciência crítica e avaliem suas condições de vida, identificando os fatores que influem negativamente na sua saúde, reivindicando os direitos de acesso aos serviços de saúde, boas condições de trabalho, habitação, entre outros. É criticado por impor uma escolha única por parte da população. $\mathrm{O}$ Modelo de Autocapacitação consiste em dar a escolha, em transmitir o conhecimento necessário para uma tomada de decisão da comunidade. Incorpora a idéia de que uma mudança democrática só pode ocorrer pela capacitação de indivíduos para modificar o seu meio. Um dos seus pontos fracos é a falta de clareza entre a aquisição de conhecimentos e as verdadeiras mudanças por parte da comunidade.

9 Para fins deste artigo, compartilhamos com a proposta de conteúdos elaborada pelo Coletivo de Autores (1992), acerca da Cultura Corporal do Movimento.

10 As escolas nas quais nos referimos aqui são o Colégio Estadual Edmundo Bittencourt, localizado em Teresópolis/RJ, e o Centro Integrado de Educação Pública Roquete Pinto, localizado em Queimados/RJ.

11 Em relação à discussão acerca da crise de identidade por um objeto de estudo na Educação Física, recomendamos a leitura do rico debate entre Go Tani (1996), Mauro Betti (1996) e Hugo Lovisolo (1996) na Revista Motus Corporis/UGF-RJ, e do debate entre Adroaldo 
Gaya (1994), Celi Taffarel e Micheli Escobar (1994), Walter Bracht (1995), Silvino Santin (1995), Paulo Ghiraldelli Júnior (1995), Hugo Lovisolo (1995), Lamartine da Costa (1996) e Gabriel Palafox (1996), na Revista Movimento/UFRGS-RS.

12 Os temas que apresentamos neste ensaio não pretendem esgotar-se em si mesmos, pois em função da realidade dos alunos (idade, sexo, classe social, localidade da escola, realidade institucional etc.), podese trabalhar com outras temáticas.

13 Tivemos a possibilidade de observar os frutos de um trabalho coeducativo, ao trabalharmos por um bimestre o conteúdo do futebol em aulas mistas, quando surgiram diversas situações-problema, tais como a cooperação entre meninos e meninas na execução das atividades propostas.

\section{REFERÊNCIAS}

ANDREWS, J. C. Educação para um estilo de vida ativo no século XXI. Revista Brasileira de Ciência e Movimento. São Caetano do Sul, v. 4, p. 43-49, 1990.

BETTI, M. Por uma teoria da prática. Motus Corporis. Rio de Janeiro, v. 3, n. 2, p. 73-127, 1996.

BRACHT, W. Mas, afinal, o que estamos perguntando com a pergunta “o que é educação Física?". Revista Movimento. Porto Alegre, ano 2, n. 2, p. 1-8, 1995.

Sociologia crítica do esporte: uma introdução. Vitória: UFES/ CEFD, 1997.

CAPARROZ, F. E. Entre a educação física "na" escola e a educação física "da" escola. Vitória: UFES/CEFD, 1997.

CARVALHO, Y. M. de. O "mito" da atividade física e saúde. São Paulo: Hucitec, 1995.

COLETIVO DE AUTORES. Metodologia do ensino de educação física. São Paulo: Cortez, 1992.

CORBIN, C. B. First things first: but don't stop there. Joperd. Virgínia, n. 52, p. 36-38, 1981. 
CORBIN, C. B.; FOX, K. Educação física e saúde: aptidão para toda a vida. Revista Horizonte, v. 2, n. 12, p. 205-208, 1986.

Aptidão cardiovascular e o currículo. Revista Aptidão Física e Saúde. São Paulo, v. 1, n. 1, p. 77-84, 1988.

CORBIN, C.; FOX, K.; WHITEHEAD, J. (1987). Fitness for a Lifetime. In: BIDLLE, Stuart (ed.). Foundations of health-related fitness in physical education. London: Ling Publishing House, 1987. p. 8-12.

DA COSTA, L. P. Uma questão ainda sem resposta. Revista Movimento. Porto Alegre, ano 3, n. 4, p. 1-10, 1996.

DEVIDE, F. P.; RIZZUTI, E. V. Transformações periféricas das representações sociais de alunos de $1^{\circ}$ grau do Colégio Estadual Edmundo Bittencourt (Teresópolis/RJ) sobre a educação física escolar após intervenção pedagógica. Anais... Florianópolis: CBCE, 1999. p. 1423-1424.

FARIA JÚNIOR, A. G. de. Educação, desporto e promoção da saúde. Oeiras: Câmara Municipal de Oeiras, 1991.

FARINATTI, P. T. Educação física escolar e aptidão física: um ensaio sob o prisma da promoção da saúde. Revista Brasileira de Ciência do Esporte. Santa Maria, v. 6, n. 1, p. 42-48, 1994.

FRANCALACCI, V. L.; NAHAS, M. V. Alterações no conhecimento, atitudes e hábitos de atividade física em universitários que cursaram educação física curricular na UFSC. Revista Brasileira de Ciências do Esporte. Santa Maria, v. 16, n. 3, p. 168-172, 1995.

GAYA, A. Mas, afinal, o que é Educação Física? Revista Movimento. Porto Alegre, ano 1, n. 1, p. 29-34, 1994.

GHIRALDELLI JR., P. A volta ao que parece simples. Revista Movimento. Porto Alegre, ano 2, n. 2, p. 15-17, 1995.

Educação física progressista. 4. ed. São Paulo: Loyola, 1992.

LOVISOLO, H. R. Hegemonia e legitimidade nas ciências dos esportes. Motus Corporis. Rio de Janeiro, ano 3, n. 2, p. 51-72, 1996.

Mas, afinal, o que é Educação Física?: a favor da mediação, e contra os radicalismos. Revista Movimento. Porto Alegre, ano 2, n. 2, p. 18-24, 1995. 
MOSSTON, M. Teaching physical education. Columbus, CE: Merril Books, 1966.

NAHAS, M. V.; CORBIN, C. B. Aptidão física e saúde nos programas de educação física: desenvolvimentos recentes e tendências internacionais. Revista Brasileira de Ciência e Movimento. São Caetano do Sul, v. 6, n. 2, p. 47-58, 1992.

PALAFOX, G. M. O que é Educação Física?: uma abordagem curricular. Revista Movimento. Porto Alegre, ano 3, n. 4, p. 11-14, 1996.

PANGRAZI, R.; CORBIN C. Physical fitness: questions teachers ask. Joperd. Virgínia, v. 64, n. 7, p. 14-17, 1993.

SANTIN, S. A respeito de comentários. Revista Movimento. Porto Alegre, ano 2, n. 2, p. 9-14, 1995.

SARAIVA, M. do C. Co-educação física e esportes: quando a diferença é mito. Ijuí: Unijuí, 1999.

SOARES, C. L. Educação Física: raízes européias no Brasil. Campinas: Autores Associados, 1994.

SOUZA DE OLIVEIRA, G. A.; DEVIDE, F. P. Proposta temática para educação física escolar no ensino fundamental: um relato de experiência. Motus Corporis. Rio de Janeiro, v. 8, n. 2, p. 80-86, 2001.

TAFFAREL, C. Z.; ESCOBAR, M. O. Mas, afinal, o que é Educação Física?: um exemplo do simplismo intelectual. Revista Movimento. Porto Alegre, ano 1, n. 1, p. 35-40, 1994.

TANI, G. Cinesiologia, educação física e esporte: ordem emanente do caos na estrutura acadêmica. Motus Corporis. Rio de Janeiro, ano 3, n. 2, p. 9-50, 1996.

TONES, K. Health education and the ideology of health promotion: a review of alternative approaches. Health Education Research. Oxford, ano 1, n. 1, p. 3-12, 1986.

WHO. Health promotion: a discussion document of the concept and principles. Copenhagen: WHO, 1984. 
Recebido:30 de março de 2004 Aprovado: 20 de abril de 2004

Endereço para correspondência Rua Barão da Torre, 445, ap. 401 Ipanema - Rio de Janeiro - RJ CEP 22411-003

E-mail: fabianodevide@uol.com.br 
